Physics Group. Well-known scientists will give their views on the role the computer has played in their field in the recent past, and is likely to play in the near future. Following the aim of the Group to interest physicists in the computational problems of other branches, the invited review papers will be given in plenary sessions throughout the period of the conference. In addition, more specialized contributed review papers will be presented in parallel sessions. It is a pleasure to acknowledge the help of CERN in realizing this project. Further details and an application form will be found on p. 7 of Europhysics News, Vol. 2, No. 3. During the conference, the Computational Physics Group will hold its first business meeting, at which the members of the Group will participate in the various administrative activities necessary for the foundation of the Group (acceptance of rules, election of a board, etc.) and will, in addition, have discussions on the future programme of the Group. The response to the preliminary announcement of the conference and to the EPS questionnaire concerning group membership has so far been very encouraging.

Meanwhile, until the conference in April 1972, the affairs of the Group are being taken care of by the interim board consisting of :
H. Bross, Munich
E. Clementel, Bologna
K. Differt, Stuttgart
M.R. Feix, Nancy
H. Grote, Geneva (Secretary)
E. Knighting, Bracknell
G.R. Macleod, Geneva (Chairman)
G.I. Marchuk, Novosibirsk
C. Moser, Orsay
C.L. Pekeris, Rehovoth
K.V. Roberts, Abingdon
R. Thirlby, Newcastle-on-Tyne
A. Vaciago, Rome
L. van Hove, Geneva
L. Verlet, Orsay

\title{
Computer Documentation: Easy Access to Scientific Knowledge
}

\section{Steinacker ESRO}

The European Space Research Organization (ESRO) maintains a large computerized documentation service for its Member States. The system which, since 1969 , has been operating via an on-line dialogue interrogation program provides an extensive coverage of scientific and engineering literature even outside the confines of space research, and is steadily enlarging its terminal network throughout Europe. Furthermore considerable efforts are made to facilitate the practical exploitation of the system by the user community.

\section{Coverage of Literature}

The ESRO/ELDO Space Documentation Service was originally based on the NASA file, made available to ESRO under a generous exchange agreement. NASA started to collect document references (see Fig. 1) as early as 1962 and by now this collection has risen to over half a million items. About half consists of 'unpublished' material (NASA, US Government and industrial reports) which is very difficult to locate in Europe but can very easily be retrieved through the computer and is also available on microfiche or as hard copy from ESRO in Paris.

This collection of unpublished material is particularly important in helping to broaden substantially the basis of knowledge in most fields of natural science and engineering be- cause it provides access to the results of advanced studies carried out in space research programmes.

The other half of the NASA collection is provided by the American Institute of Aeronautics and Astronautics (AIAA) which regularly scans about 1500 periodicals for articles falling within the very broad scope of NASA interests. Bibliographic references are extracted from the original literature only and not from abstracts journals. The NASA file thus constitutes an abstracts journal on magnetic tape, and the computer printout (Fig. 1) contains not only the title but also a short notation of content and a list of scientific terms (descriptors) identifying the subjects treated in the document.

As the 1500 journals scanned by the AIAA do not cover a sufficiently broad section of the general literature, ESRO is adding other magnetic tape services to the collection. Among the services already available or shortly to be provided are the METADEX tapes produced by the American Society of Metals, a collection which since early 1969 has grown by about 25000 references per year, the US Government Research and Development Reports (growth rate about 50000 items per year) and the Engineering Index (growth rate about 60000 items per year).

Thus the collection of bibliographic references maintained by the ESRO/ ELDO Space Documentation Service

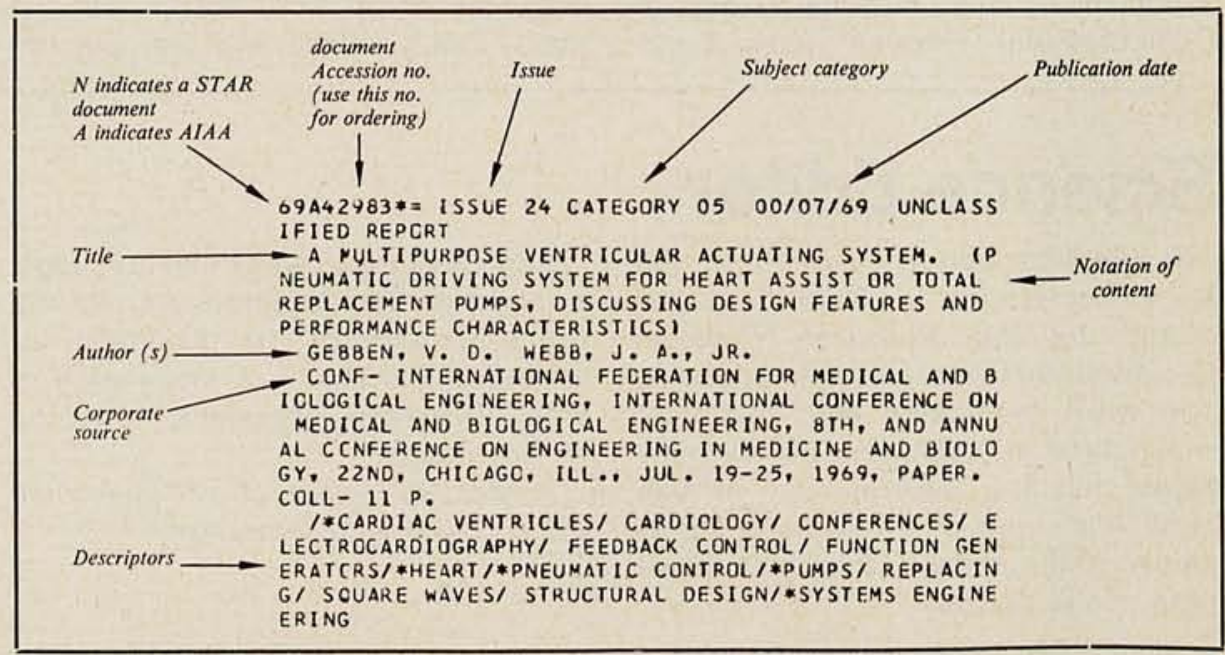


will eventually become the most comprehensive one accessible via a dialogue interrogation system, providing much assistance to scientists and engineers wishing to know the latest developments in their respective fields.

\section{Growth of the System throughout Europe}

At ESRO headquarters in Paris an interrogation terminal was installed in 1969 when the system became available (Fig. 2). Since then, several other consoles have been added or are being connected in other ESRO member countries; further terminals are under negotiation (Fig. 3). The ESRO/ ELDO Space Documentation Service is thus growing rapidly and is acting as a pilot system leading to more efficient methods of transferring knowledge and exploiting technology.

\section{Helping the User Community}

The ESRO/ELDO Space Documentation Service is a novel concept and its operation differs considerably from those of conventional documentation or library services. To promote understanding of the use of computers for literature searches, members of the staff travel throughout Europe visiting industrial companies, universities and research institutes to present the service and to discuss on the spot the requirements of the users. Three different types of service are available to answer most of these requirements :

- Retrospective Bibliographies: tailor-made searches for one user only, from the present back to 1962.

- Monthly Services : tailor-made SDI (Selective Dissemination of Information). One service (12 issues) runs for one year.

- Industrial Topics/Standard Profiles: standard monthly services with about 200 titles available (12 issues).

Two years' operational experience have revealed a number of facts that should be kept in the users' mind so that an efficient 'interface' may be created with such a computer service.

Although a computer cannot be used to simulate intelligent human behaviour it will serve as a very efficient instrument for data reduction. With its aid in searching data files a documentalist at the console can in under an hour reduce a collection of about $10^{6}$ items to a subset of $10^{2}$. The person working through this reduced output is able to establish interrelations between the search problem posed, the titles retrieved and the descriptors assigned to each title and document. As this output can be viewed during a search on the console, it is possible to modify the scope of a search by adding, deleting or
Fig. 2: First terminal installed at ESRO headquarters at Neuilly showing control unit (bottom). keyboard, display screen and teletypewriter for logging search procedures. The bibliographic printout is produced on a high speed printer.

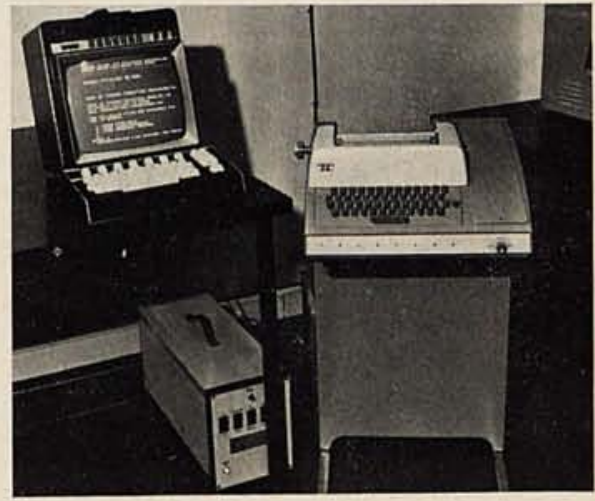

regrouping descriptors until the result is satisfactory. The same possibilities are open to the user concerning the printed bibliographies, and proposals to improve searches can be accommodated by the service. The whole may be compared to a feedback control system in which the input variables (search descriptors) of a process (computer search) are modified in view of the output (references retrieved). This type of work differs fundamentally from ordinary computer operations where, normally, the machine operates by defined procedures on defined data. In information retrieval the computer deals with a data structure affected by context. This is one possible reason for the difficulties encountered by the user community in grasping the full implications of such a computer service. At the same time this field offers much scope for further research in the information sciences.

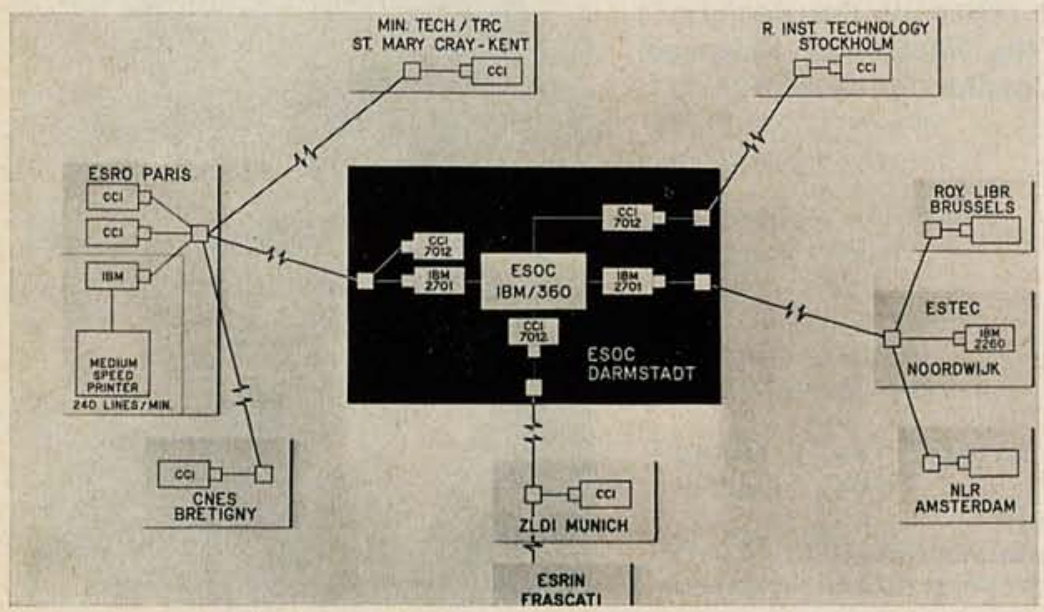

Fig. 3: Distribution of terminals in ESRO member states. 